\title{
CUERPO Y ESCRITURA. LOS GLIFOS FOTOGRÁFICOS DE LEANDRO KATZ
}

\author{
CARINA GONZÁLEZ \\ Universidad Nacional de Mar del Plata \\ CONICET- CELEHIS \\ farruggio@gmail.com \\ ORCID: 0000-0002-0471-679X
}

\section{RESUMEN}

Durante el siglo $X X$, los estudios sobre el cuerpo han adquirido un matiz filosófico que lo cuestionan como territorio de la identidad. Desde esta perspectiva el cuerpo es una construcción simbólica que se crea más allá de lo material, en donde intervienen distintos sistemas de representación. Este trabajo analiza una instalación de Leandro Katz (1938) en la que el artista explora la relación particular entre cuerpo, muerte y fotografía. A partir de la intervención de la imagen por lo textual, se examinan las formas en las que el cuerpo produce y recupera sentidos para hacer consciente su propia potencialidad.

PALABRAS CLAVE: cuerpo, Che Guevara, guerrilla, glifos, fotografía.

\section{BODY AND WRITING. THE PHOTOGRAPHIC GLYPHS OF LEANDRO KATZ}

\section{ABSTRACT}

The body was subject of important philosophical studies during twenty century. Focusing on its inability to determine identity, the new approach considers body as a symbolic construction that goes beyond the physical world where multiple representation systems takes place. This work analyzes Leandro Katz's (1938) installation through his singular exploration of the relation among death, body and photography. Based on the intervention of the images by a textual element this essay examines modes in which body produces and recovers senses of its own potency.

KEYWORDS: body, Che Guevara, guerrilla, glyphs, photography.

\section{LOS SENTIDOS DEL CUERPO}

El cuerpo ha sido objeto de reflexión de numerosas disciplinas como la biología, la anatomía y la filosofía. Sin embargo, desde la antigüedad se ha estudiado a partir de su dimensión binaria, liminalmente unido a esa otra parte que lo completa o contradice, ese otro lado encarnado en el alma, el espíritu o el pensamiento. Así, el cuerpo transformado en materia, en lo sensible, en res extensa capaz de ser visto, tocado y acaso también expropiado, se experimenta como una sensación, un escalón misterioso pero necesario para acceder a la subjetividad. Desde la racionalidad, la máxima cartesiana sobre la que se fundó la modernidad, «Pienso luego existo», ignora la potencia de los cuerpos que fueron capaces de 
producir, junto al pensamiento, las transformaciones fundamentales de la Revolución francesa. Ese mismo cuerpo capaz de enfrentarse al poder, obtiene una victoria mucho más profunda que la política porque conquista un espacio individual en el que se vuelve clave para el entendimiento y para la transformación del ser en sujeto. Por eso, Spinoza reclama «nadie ha determinado por ahora lo que puede un cuerpo» (2000: 128) y coloca la ética en el centro del contacto entre los cuerpos, cuerpos que afectan a otros cuerpos, o cuerpos que son afectados por otros, movidos por acciones y pasiones que los relacionan, que los potencian. Estos cuerpos recuperados para la ética, adquieren un protagonismo que es, por un lado, la revelación de su potencia, la conciencia de todo lo que pueden producir y hacer, la posibilidad del cambio; por otro, la declaración de peligro, la certidumbre de una amenaza que debe ser controlada como lo fue en la antigüedad por la razón. La construcción moral y religiosa que separa el bien del mal, que regula lo instintivo con lo racional, que vigila lo carnal con lo espiritual, acciona como fuerza que debe vigilar y controlar esos cuerpos amenazantes. Foucault advierte en sus estudios sobre las prisiones y los hospicios el encierro de esos cuerpos recluidos por la enfermedad, por el crimen o la locura, que es la forma con la que el estado moderno declara la normatividad. Pero también Agamben retoma las ideas de la biopolítica para señalar la manera en que, desde la antropología moderna, se legisla sobre la vida. El cuerpo en este estado de excepción es un despojo, donde la antigua división entre materia y espíritu es sustituida por la de una vida desnuda. Un cuerpo que pierde su capacidad de contactarse con otros cuerpos, un cuerpo reducido a merced del Estado, una vida atravesada por la ley, una vida puesta en juego.

Desde este mismo lugar de excepción donde la ley se anula a sí misma, jugarse la vida es impulsar el cuerpo hacia adelante, devolverlo al territorio de lo pensante en el que la razón y lo sensible se mezclan. «Somos un cuerpo» (2003: 14), señala Nancy para enfatizar la condición siempre relegada de la materialidad, pero también para establecer el carácter ambiguo de la identidad, poniendo en perspectiva la cuestión del ser, no el ser pensante sino el ser carnal que, lejos de la terrenalidad cristiana, coloca a la subjetividad en el cuerpo y a ese cuerpo en el centro de una propiedad incierta, falsa o acaso desencajada. A partir del trasplante, de la posibilidad tecnológica de intervenir sobre el cuerpo, las prótesis modernas incorporan lo ajeno a lo propio, esa externalidad que avanza sobre el ser para recordarnos que el cuerpo no nos pertenece, que está tocado desde su origen por la viscosidad de la muerte y que durante su existencia definirá su posición interna ante lo pensante pero también como amalgama de esa razón, su posición externa ante el poder, el saber y las instituciones que intentan dominarlo. Esta condición de impropiedad siembra también la duda sobre la antigua certeza de su materialidad; así el cuerpo cuestiona además su naturaleza sensible para exponerse como una continuidad de la inmaterialidad del alma. Desde una de las más fuertes apreciaciones religiosas, Nancy examina las posibilidades significativas del «He ahí mi cuerpo»y descubre una presencia 
siempre diferida, una naturaleza desplazada hacia el lugar de lo simbólico, un cuerpo que es siempre otra cosa, pan y vino, o el cuerpo colectivo de la comunión, o el cuerpo Absoluto, resumido como la presencia de una ausencia. Así presentado, el cuerpo ampara una contradicción que señala el vacío o, más precisamente, el lugar de una existencia que no tiene esencia.

Por eso es que la ontología del cuerpo es la ontología misma: Ahí el ser no es nada previo o subyacente al fenómeno. ¿El cuerpo es el ser de la existencia? Cómo mejor tomarse la muerte en serio. Pero también cómo decir que la existencia no es para la muerte sino que la muerte es su cuerpo. No hay la muerte como una esencia a la que estuviéramos avocados sino que hay el espaciamiento mortal del cuerpo que inscribe que la existencia no tiene esencia (ni siquiera la muerte) sino que solamente ex - iste. (Nancy 2003: 16, énfasis nuestro)

Esta relación entre lo extenso del cuerpo y la muerte, entre esa presencia que se sustrae a lo puramente material, expresa además una existencia discursiva que se manifiesta como índice, como la señal de un sentido para siempre desplazado. La frase ritual, el «He aquí mi cuerpo», inquieta no solo por la ubicación del cuerpo en una visibilidad incierta sino porque pone en escena la desnudez de la representación. Eso que está ahí es un señalamiento, lo que ocupa en ese momento el lugar del cuerpo que ya no está allí. Una existencia deíctica que traslada el sentido fuera de lugar, diferido o vaciado en numerosas mutaciones.

Nos interesa señalar que, desde una perspectiva visual, ese desplazamiento del cuerpo que muestra el vacío tiene un vínculo singular con la fotografía. También la foto es un deíctico que esconde el referente, porque el objeto de una foto es siempre alguien o algo que estuvo allí y ya no está. Barthes lo explica como un gesto extremo que expresa la contingencia absoluta. «La fotografía dice: esto es esto, es asá, es tal cual y no dice otra cosa (una foto no puede ser transformada (dicha) filosóficamente), está enteramente lastrada por la contingencia de la que es una envoltura transparente y ligera» (1989: 29). No es una foto sino ésta foto en particular lo que atrae el índice de eso que es «el encuentro con lo Real en su expresión infatigable» (Barthes 1989: 29). Las dos definiciones ponen en evidencia lo impalpable del cuerpo que es atravesado por la fijación de la fotografía en un esfuerzo frustrado por asirlo. En este sentido, la fotografía se acerca a la conceptualización filosófica del cuerpo señalando también la doble vinculación con el vacío y con la muerte. Por un lado, el retrato es un cuerpo desplazado por la mecánica de su reproducción; por otro, la foto es la contabilización del tiempo diferido, el estar ahí de un tiempo muerto que ya pasó. Sobre todo en el retrato o en las fotos documentales ese correr hacia el vacío se manifiesta como un instante atrapado por lo tecnológico en un dispositivo que hace de lo simbólico su materialización. La foto nos dice más de lo que la cámara captó en el momento fugaz de la aparición de los cuerpos, pero también comprueba la descomposición de esa materialidad que existe hacia la muerte. El retrato de los muertos como recuerdo encierra en sí mismo el objeto de toda 
fotografía, repetir hasta el infinito el corpus que necesitó ese cuerpo que aparece como fantasma. Quizá por eso Barthes habla del spectrum, del objeto como espectáculo y de cómo la fijeza de la foto contrasta con lo cambiante del sujeto que deviene objeto y que, a través de la pose, mortifica su cuerpo ante la cámara en un acontecer estático que reproduce la inmovilidad de la muerte.

Este cruce entre los estudios del cuerpo y la fotografía tiene en las artes visuales una aparición productiva. Pero es, sobre todo, la encrucijada con la muerte lo que hace de la obra de Leandro Katz (1938) una exploración de la corporalidad del sentido, en tanto sentido de los cuerpos - cuerpos expuestos, derruidos, arrojados fuera de sí-, y en tanto cuerpos de sentido - montados, multiplicados, puestos en relación con otros cuerpos. En muchos trabajos Katz parte de una foto para realizar su obra, pero nunca esa foto adquirió un rol tan protagónico como en el «Proyecto para El día que me quieras» (1997), una instalación que tiene como punto de partida y como materialidad la foto emblemática del cadáver del Che, mediante la cual se explora el concepto de cuerpo y muerte. A partir de la ausencia del objeto/cuerpo, una ausencia que es presencia material de otra cosa, Katz ha creado una manera de leer los cuerpos que mezcla la condensación de la imagen y la codificación de lo textual. El artista parte de una foto, la foto de un cuerpo, para mostrar lo que ese cuerpo es capaz de decir, lo que ese cuerpo hace advenir en aquel que lo recibe a partir de la muerte sabiendo que la referencia a la muerte es parte inseparable, tanto de la reflexión que imponen los cuerpos de Nancy, quien habla de un «espaciamiento mortal» como de la descripción de la fotografía de Barthes, quien la vincula a una micro-experiencia de muerte, la fijación de lo cambiante del sujeto en una pose que «mortifica» el cuerpo (Nancy 2003: 37).

El vínculo entre fotografía y muerte no alcanza, sin embargo, para explicar la riqueza semántica que Katz le otorga a esta imagen «intervenida» ya que lo que importa en su intervención artística es el montaje capaz de introducir nuevos significados. Influenciado por la lógica visual de los glifos mayas, Katz explota la arbitrariedad de todo sistema de comunicación que aún en los enigmas encriptados de la imagen se hallan estructurados a partir de un código. Por medio de un procedimiento que extrae de la historia del arte, el díptico, Katz propone un montaje en el que la imagen reproduce los dos elementos del signo textual esta vez desencajados de su propio código. Esta técnica unida a la plasticidad semántica del jeroglífico le proporciona un modo particular de implementar la relación texto-imagen. Katz explica que los sistemas idiogramáticos están tan codificados como cualquier alfabeto solo que falta descubrir cuál es su lógica.

Esto estaba vinculado a mi fascinación por las palabras, el lenguaje, los jeroglíficos, en particular los ideogramas, los pictogramas, las organizaciones alfabéticas de los mayas. ¿En qué consisten éstos, cuáles son las escisiones? Hay pequeñas estructuras individuales con prefijos, sufijos, afijos y postfijos. Tienen significados cardinales que modifican el 
significado del glifo central. Esa riqueza lingüística me recuerda a la gramática francesa. (Reynaud 2013: 31) ${ }^{1}$

El díptico trata de vincular la imagen con la lectura textual que lee en el signo su división binaria entre significado y significante. Esta perspectiva que desestima la naturalidad de una lengua enfatizando su alto grado de codificación puede relacionarse con la fragilidad y la arbitrariedad de los sistemas de comunicación que siempre lo apasionaron, desde la creación de sus primeros alfabetos hasta la internalización tecnológica de la estructura del signo lingüístico en algunos de sus proyectos fílmicos. ${ }^{2}$

Sobre este inicio visual de la foto de un cuerpo muerto o de un cuerpo glifo, se construye un significado diferido que el espectador debe elaborar a partir de una mirada deambulante que no se queda en la estructura fija del signo, sino que interviene en la obra transformándola y buscando nuevos significados.

En las páginas que siguen analizaremos cómo se manifiesta la relación entre imagen y texto a través de los dípticos montados sobre una idea que, si bien parte de la imagen fotográfica, elabora un tejido textual en donde los cuerpos se reúnen con otros cuerpos de sentido.

\section{EL CUERPO AUSENTE}

El «Proyecto para El día que me quieras» es una instalación que Katz monta para conmemorar los treinta años de la muerte de Ernesto Guevara. Desde 1997 hasta el 2017 esta muestra fue transformándose a través de elementos que el autor le agrega ya sea para completar su primera investigación o para extender los lazos significantes hacia otras formas de la acción política. En este caso, nos centraremos en la instalación exhibida en PROA durante el 2018, en donde el material se presenta desde su punto inicial, como proyecto para un film documental y se completa con otras presentaciones en forma de texto murales, fotos proyectos y films también basadas en un primer dispositivo fotográfico. Fiel a la apreciación de que la obra de arte no es el resultado sino la materialización de todo un proceso, el artista compagina los fragmentos heterogéneos que intervienen en la película documental del mismo nombre que terminó de concretarse en 1997. La investigación fue llevada a cabo durante la década del 80, periodo durante el cual Katz atraviesa la geografía de la guerrilla, acompañando los pasos del Che por la selva boliviana. En este recorrido, el artista arma una cronología de los últimos días de Guevara, pero su estudio parte de una foto

\footnotetext{
1 En sus Alfabetos Katz desarrolla una nueva codificación utilizando lo idiogramático. Los elementos de estos alfabetos inventados sustituyen las letras por imágenes de la luna, de caracoles, o de molinos de viento.

${ }^{2}$ La misma técnica inspira su film La Escisión (1978) basado en Emma Zunz de Borges en el que aparece la pantalla dividida en dos mitades que representan la estructura binaria del signo.
} 
emblemática, la foto del cadáver del Che exhibido y expuesto por los militares bolivianos, la foto tomada por Fredy Alborta que sirvió como una confirmación de su muerte y como seña de identidad ante los medios y organismos internacionales. Una foto documental, histórica y mitológica que es, al mismo tiempo, la manifestación de una verdad y el ocultamiento de otra.

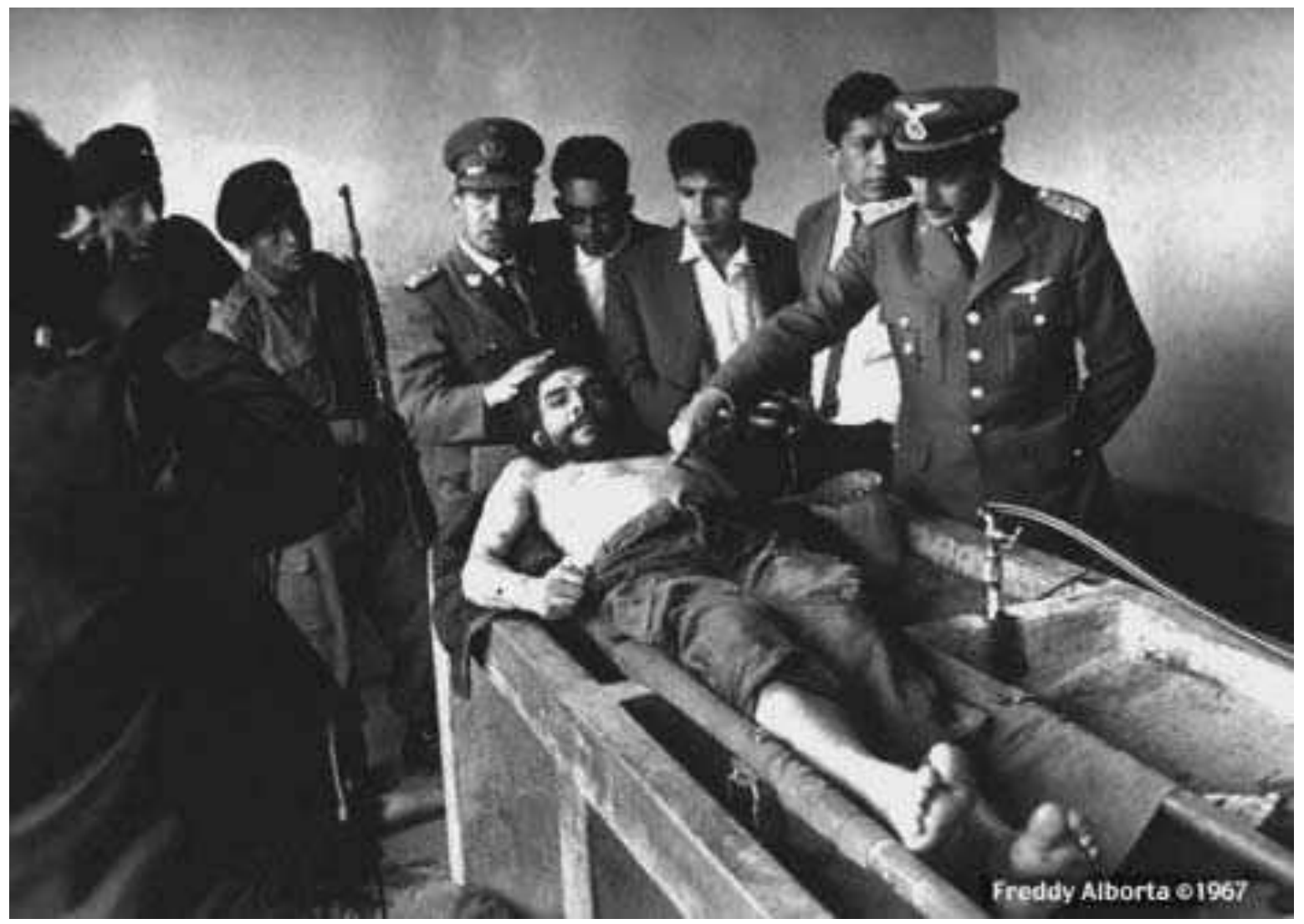

Figura 1. Archivo fotográfico de Freddy Alborta, disponible en: <http://www.leandrokatz.com/Pages/El\%20Dia\%20Spanish.html>.

En esta foto emblemática, el cuerpo sin vida de Guevara aparece tendido en una de las piletas de la lavandería de Vallegrande. Se trata de una foto singular por su alto contenido político, pero no exclusiva porque ha sido seleccionada entre otras muchas versiones y además ha sido editada y corregida por el ojo técnico de la cámara, a través del marco, de la iluminación y de la perspectiva. John Berger ha comparado la puesta en escena de la foto con «La lección de anatomía» de Rembrand, los militares observando y explorando las cualidades de un cuerpo muerto, lo que este cuerpo significa y lo que este cuerpo todavía puede hacer desde la muerte. Un cuerpo expuesto, manipulado para mostrar su identidad, los ojos abiertos, el brazo del general señalando, los subordinados aprendiendo quizá cuáles son las consecuencias fatales de que los cuerpos se rebelen. La función de las dos imágenes es la misma, «hacer de los muertos un ejemplo: en una, para el avance de la medicina; en la otra, como una advertencia política» (Berger 2010: 23). Sin embargo, esta foto que repetirá para siempre la muerte del guerrillero no es la única. En la entrevista incorporada al documental, 
Freddy Alborta relata cómo fue su experiencia al fotografiar esa muerte y comparte con Katz las tomas descartadas de otras versiones menos comprometidas con lo que el ejército quiere mostrar. Ahí en el fuera de campo, en el punto ciego donde Barthes ubica la punzada del azar, la herida de la foto que roza al espectador, aparecen otros cuerpos, el de Willi (Simón Cuba) y el Chino (Juan Pablo Chang Navarro); cuerpos que fueron expulsados de la escena, los cuerpos mutilados de otros guerrilleros que murieron con Guevara, que fueron recortados de la foto pero que reintegran al Che con el cuerpo colectivo de la guerrilla.

Estos cuerpos ubicados en el margen son para el artista, el punctum, la flecha que reordena la lectura, la posibilidad de hallar un sentido otro más allá del contexto codificado en el testimonio político o el cuadro histórico. Esos cuerpos perturban al espectador, son lo que Barthes definió como un suplemento, la herida que corta la participación de lo culturalmente representado y que se impone como parte de una narración que da movimiento a la imagen. De este modo, la foto pierde la fijeza que la asimila no solo a la muerte sino a la convalidación de una verdad hegemónica (alidada del sentido único y unidireccional) para congregar otro tipo de semántica amparada en lo diverso que hace posible la contradicción, la discusión y la lucha por el significado. Esa ampliación del sentido que no está codificada y que requiere de la subjetividad de la mirada revela el contacto de los cuerpos, el de los muertos de la Revolución, pero también el del espectador que mira más allá de la foto para darle a esas muertes un significado distinto, suplementado.

El punctum es entonces una especie de sutil más-allá-del-campo, como si la imagen lanzase el deseo más allá de lo que ella misma muestra: no tan solo hacia el resto de la desnudez, ni hacia el fantasma de una práctica, sino hacia la exhibición absoluta de un ser, alma y cuerpo, mezclados. (Barthes 1989: 99)

Esa doble articulación entre lo que se muestra y lo que se excluye origina la duplicidad que Katz busca en la exposición de sus propias fotos, una instalación basada en los dípticos medievales o góticos, pero también en la dicotomía entre significado y significante. Sabiendo que esa relación es arbitraria Katz busca que la mirada escriba su propio texto, es decir, que decodifique el vínculo binario del díptico que se expandirá en lo paradigmático de la unión entre esos dos elementos. De este modo Katz recupera el cuerpo colectivo de la guerrilla armando un código de lectura que da cuenta de las lecturas políticas, filosóficas y artísticas de esa foto en particular, la disección del cadáver como una lección de anatomía, no en aras del saber sino como certificación de muerte, y la identificación del Che con el Cristo caído de Mantegna (Berger 2010: 24). Ambas imágenes aparecen en la instalación en forma de díptico que no solo ilumina la comparación, sino que se propone como la lectura misma del signo, significante y significado, corridos de su espacio textual. 


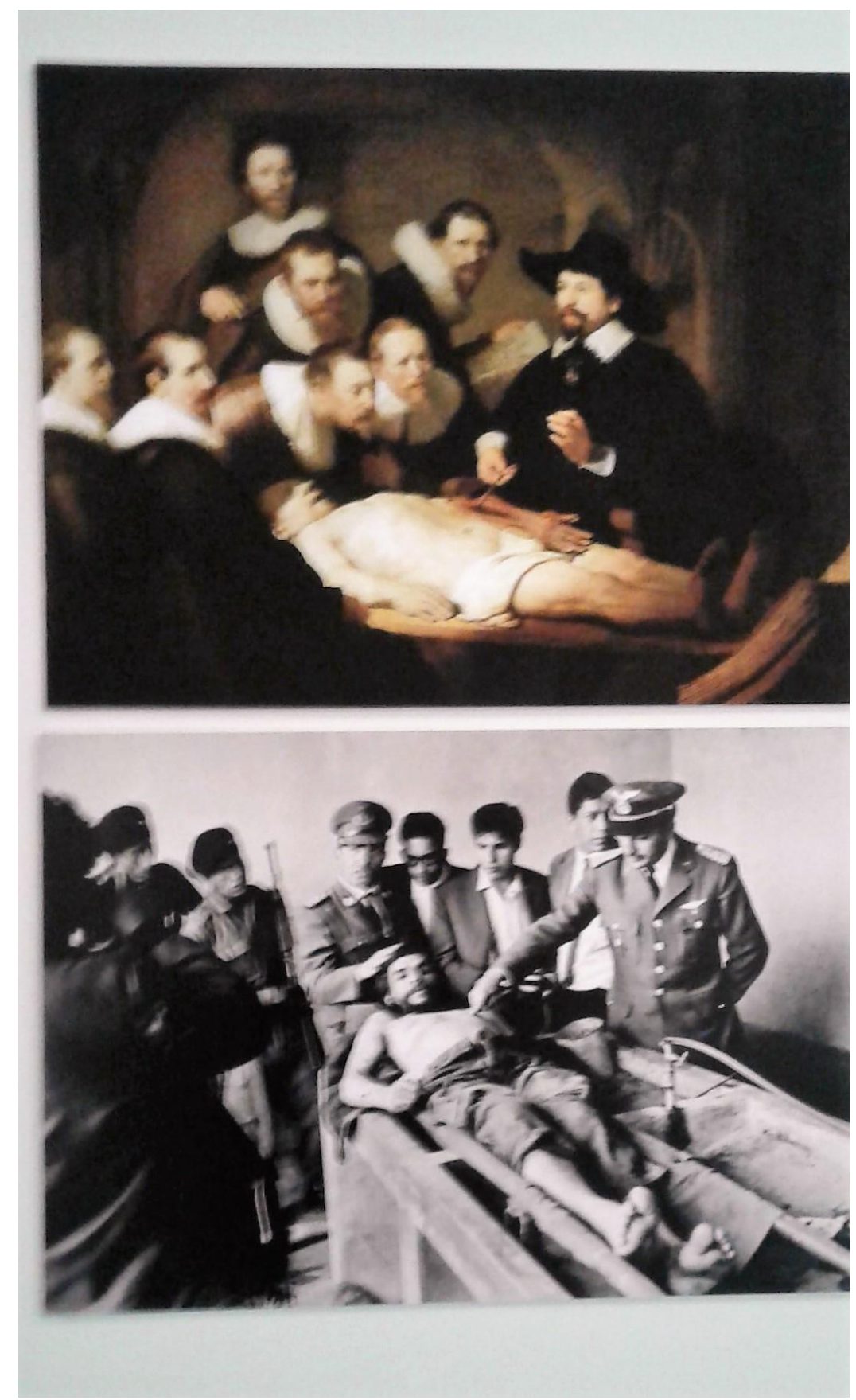

Figura 2. «Proyecto para El día que me quieras», Instalación PROA, toma personal.

Sin embargo, el elemento extraño de esa serie es el díptico que muestra a Guevara frente al Chino, en franca oposición que es, en realidad, una devolución, la puesta en contacto con otro cuerpo, la aparición de los restos, aquello que marca lo residual, la materialidad de los cuerpos que mostrados en toda su abyección no pierden sin embargo su potencia, su capacidad de afectar a otros cuerpos pero también al espectador a quien ese cuerpo revelado le llega como aparición, le adviene desde otra historia capaz de construir otro relato de esta muerte. 


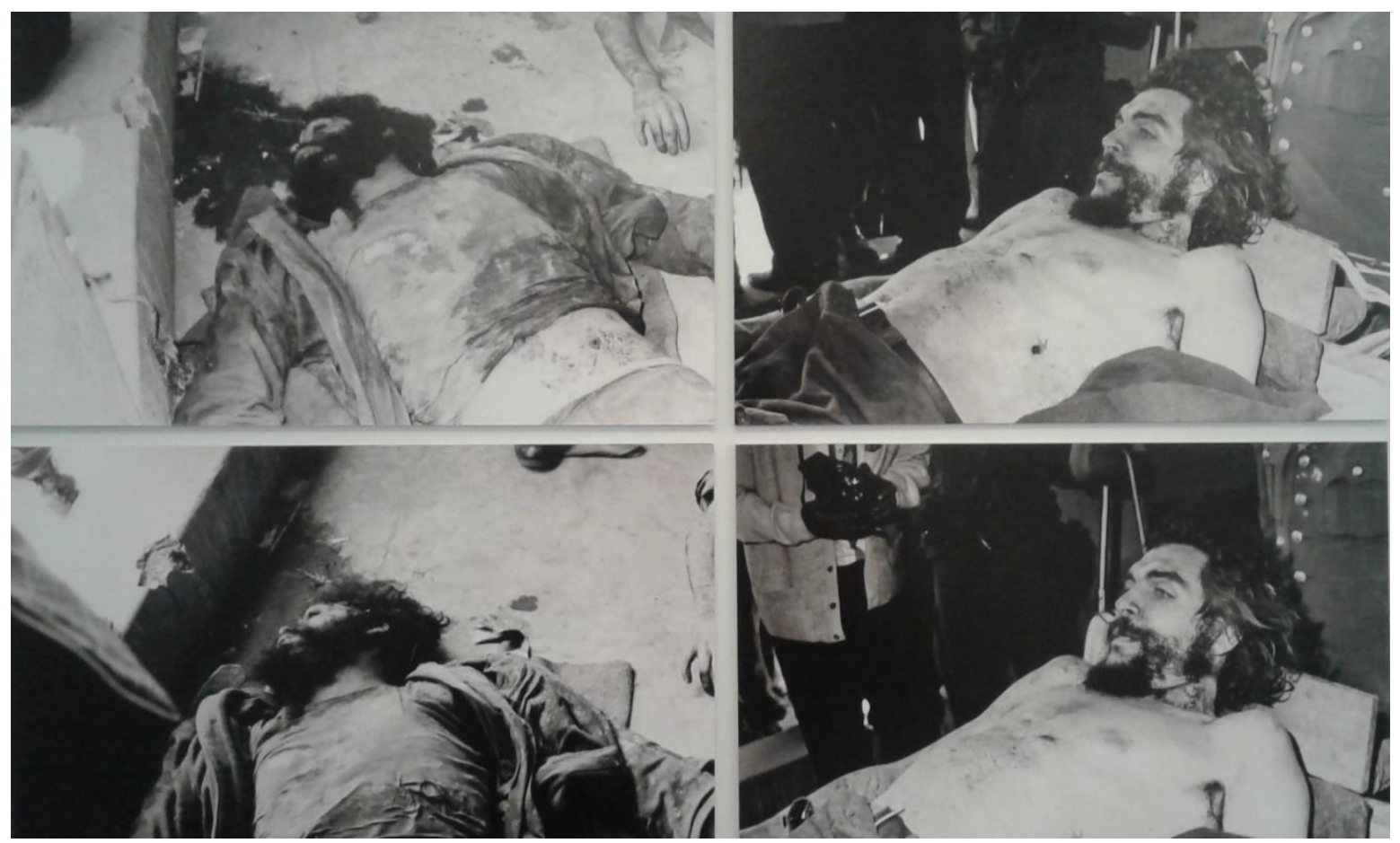

Figura 3. «Proyecto para El día que me quieras», Instalación PROA 2018, toma personal.

Esa reunión de Guevara con sus compañeros en la muerte trasciende la forma del díptico hacia el final del recorrido. Lo dual, la barrera invisible que señala lo arbitrario del signo, Cristo/el Che - el universo semántico del sacrificio, de la comunión, del paraíso por venir, etc. -, el saber/el poder - la lección ejemplar que sobre el cuerpo ejecutan la ciencia y el Estado-, dispara un abanico que despliega lo paradigmático del signo y que encuentra otro modo de representación en el mosaico. Cuerpos mutilados, fragmentados y vueltos a unir, mostrando sus costuras, sus costados, como los cuerpos que los resurreccionistas desentierran para iluminar el lado oscuro de la Ilustración. 


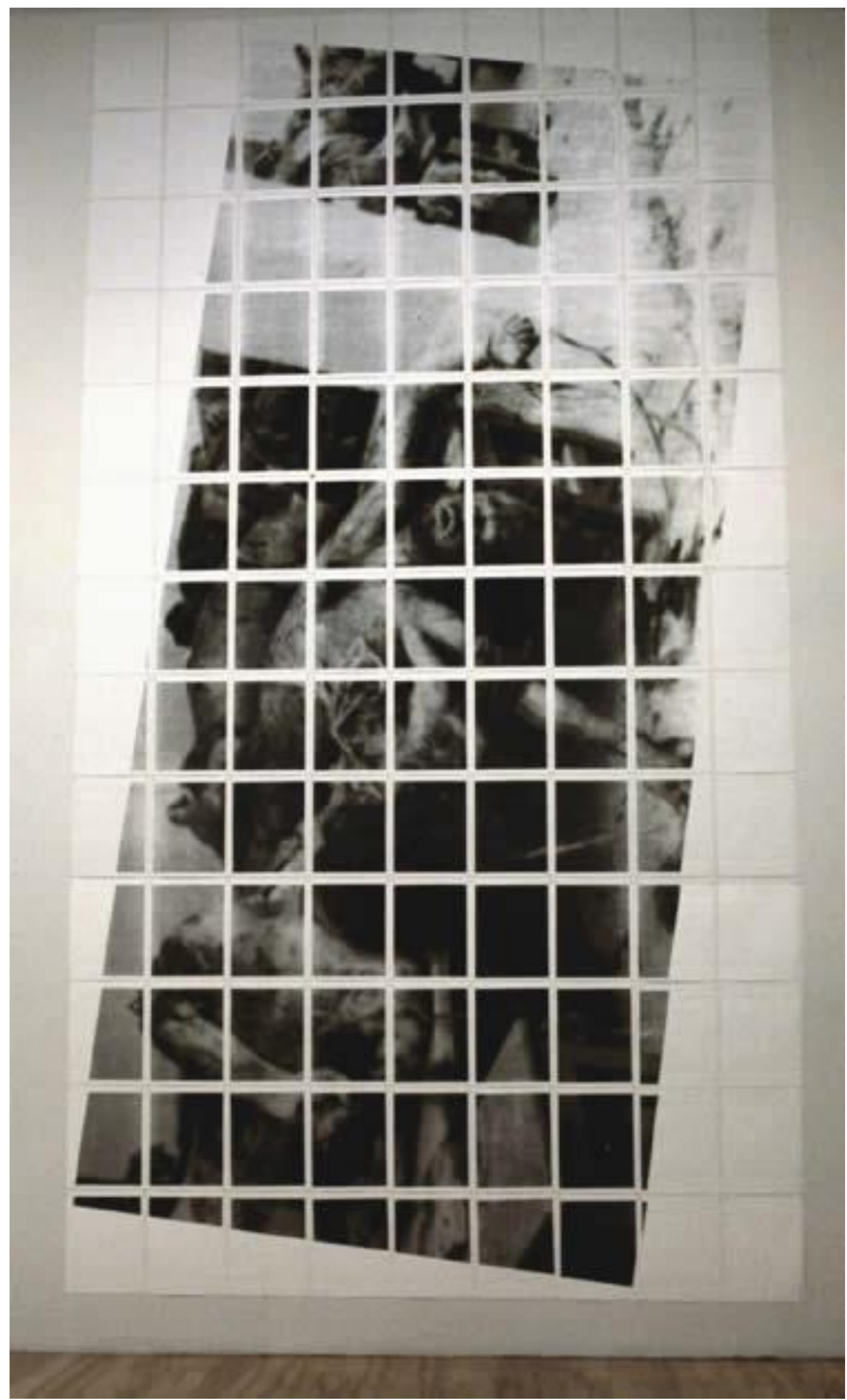

Figura 4. La columna de Joaquín, «Proyecto para El día que me quieras», Apex Art, New York, disponible en:

$<$ http://www.leandrokatz.com/Pages/Proyecto\%20Day.html $>$. 
En todas sus exhibiciones, Katz va sumando nuevas facetas de su investigación documental y de su exploración estética. «La columna de Joaquín» muestra una acumulación de cuerpos, partes que no se reconocen desde lo individual sino como partes del cuerpo orgánico que encuentra su potencia en el contacto, en la decisión de ponerse en movimiento. Así presentado, el mosaico repone lo colectivo de ese cuerpo guerrillero sin olvidar las heridas, cortes que permiten ver el todo sin ignorar lo que a ese cuerpo le costó su potencia. Esa exposición de lo colectivo fragmentado es una evidencia de la herida, pero también un eco que recuerda otros cuerpos caídos. En 2007, Katz incorpora a la instalación el film documental Exhumación, donde entrevista a Alejandro Incháurregui, miembro fundador del equipo de antropología forense, que realiza el examen para determinar la identidad del cadáver del Che, pero también los que devuelven la identidad a los miles de desaparecidos de la última dictadura militar. De esta manera, las imágenes vuelven al mosaico, donde lo doble se vuelve múltiple, donde el signo se vuelve texto, para representar el cuerpo colectivo de la revolución, cuerpos mutilados, deshechos y apilados que rememoran los tantos holocaustos de la historia, cuerpos fracturados por la intervención artística que los presenta como fragmentos de un todo vuelto a componer. Así «La columna de Joaquín» adquiere otro reflejo en el collage fotográfico de los desaparecidos, una construcción mural que, desde los organismos de derechos humanos como Abuelas, circula para recuperar la memoria y la identidad de las personas asesinadas por las Fuerzas Armadas; imagen que abre la narración visual de Exhumación.

El cuerpo transformado en una suma de otros cuerpos es ahora el cuerpo de una comunidad; esta aglomeración lo recupera como definición política, el cuerpo en relación; el cuerpo de un pueblo, el cuerpo de la patria, el cuerpo de la guerrilla.

\section{ESCRITO CON EL CUERPO}

Según Nancy, el programa de la modernidad fue escribir el cuerpo, no la corporeidad o las imágenes sino al cuerpo mismo; un cuerpo que solo puede ser mostrado, «tocado» por la escritura de la que es su parte significante (Nancy 2003). Esa unión entre cuerpo y escritura se realiza en los límites de ambos, en el extremo donde se junta lo sensible del cuerpo con lo inmaterial del sentido. Al ubicar el cuerpo en la excritura, Nancy indica su inscripción en el afuera, es decir, un más allá del texto que lo descifra como un cuerpo arrojado allí en los límites del sentido. Desde esta perspectiva, el objeto de la escritura no es mostrar el significado sino señalar el sentido que, como en la frase ritual, se encuentra siempre fuera de sí. 
Lo que le ocurre a la escritura es más precisamente tocar el cuerpo (o más bien, tal o cual cuerpo singular) con lo incorporal del sentido. Y, en consecuencia, hacer que lo incorporal conmueva tocando de cerca, o hacer del sentido un toque. (Nancy 2003: 14)

Katz realiza una operación de excritura que recupera el cuerpo excluido o mutilado y lo pone en relación con la diversidad de sentido, con una proliferación semántica que es más propia de los glifos o ideogramas que de la escritura alfabética de la que, sin embargo, copia su lógica binaria, pero alterando el código textual. De este modo, el espectador pone en ejercicio una mirada que duda capaz de sugerir más que de unificar el sentido. Al mismo tiempo, la excritura del díptico asume el movimiento de la imagen que conmueve al espectador desde el puctum, aquello que lo adviene, lo perturba o lo «toca» de un modo singular.

La elección del tema, el cadáver del Che, pero también los cuerpos muertos y marginados en el fuera de campo de la escena, indica un interés por colocar el cuerpo como excritura. Por esta razón, Katz no se aboca simplemente a representarlo, sino que arma un corpus que, mediante el contacto de estos cuerpos abandonados, arrojados fuera de sí, son dados al tacto para que cobren sentido en ese límite. Según Nancy, los cuerpos así expuestos son leídos como corpus una recolección arbitraria que recupera cada cuerpo en su ex-cripción, en su inscripción hacia el exterior, en ese espacio abierto que es lo «propiamente espacioso» y que arma otro sentido para este cuerpo sin partes, funciones o finalidades. Aquello que el filósofo francés proclama, haría falta un corpus, «la enumeración de un logos empírico, sin razón trascendental, una lista entresacada [...] una yuxtaposición sin articulación, [...] con una ordenación imprecisa y siempre extensible» (2003: 40), Katz lo lleva a cabo al superponer imágenes que, al no estar articuladas como texto, no sujetan el sentido a la armazón del signo lingüístico pero lo ponen en relación con un relato que es siempre incompleto, incierto y por ello infinito.

En el film documental El día que me quieras (1997), Katz sigue añadiendo cuerpos a este corpus. La foto inicial del Che no es la de Alborta sino la de Joseph Scherschel. Sobre las imágenes en movimiento se escucha la letra de un tango de Gardel que relata la ilusión de un amor profundo hecho realidad, «El día que me quieras». Luego otra voz lee un poema de Borges, «El testigo», donde se narra la muerte de un hombre como símbolo de la muerte de un ideal. Más allá de las repercusiones que esta letra genera en torno a la Revolución, está la geografía de Ilabaya y Nancahuazú en los Altos de los Andes, una banda roja que raja el valle marcando el horizonte. El Che, frente a Gardel, Borges y Bolivia recrean el corpus que, junto a otros textos murales como Che en Bolivia: Una Cronología (1995-1997) y a otros proyectos fotográficos como Tania: Máscaras y trofeos (2007), completan la instalación acumulativa de los cuerpos de la guerrilla.

En el documental, la secuencia de imágenes y la superposición de otros textos, el poema y el tango, no escapan a la linealidad del sintagma que construye toda narración. Sin embargo, Katz retoma la representación del díptico en una escena que logra suspender el sentido, una vez más, en la dimensión dialéctica 
del ideograma. De repente una línea roja corta el horizonte y divide la pantalla en dos, cercando el cruce de una columna de guerreros por el valle. Esta fractura connota una relación con el signo, la búsqueda de una metáfora que resuma la idea del díptico. Para Katz, se trata de intervenir la imagen con algún elemento que remita al signo textual y que permita recomponer otros significados.

La idea de la barra inclinada hacia la derecha, como en $\mathrm{Y} / \mathrm{O}$, la de la ambigüedad, era el diseño visual que me interesaba materializar moviendo las banderas a través de campo y sobre la cabeza de los actores. Esto no significa que estaba "nadando entre dos aguas" políticamente sino que quería presentar la opción alternativa. Este es el umbral. (Reynaud 2013: 33)

Un umbral que se ubica entre el texto y la imagen pero que también caracteriza la exploración de medios y lenguajes de Katz, ubicado siempre en el pasaje entre la poesía, la plástica, la fotografía y el cine o entre el español, el inglés, los ideogramas antiguos y los alfabetos occidentales. La barra inclinada, el signo de igualdad, el de equivalencia y el de infinito son elementos gráficos que el artista utiliza para crear otra especie de díptico en una muestra más reciente. Katz se refiere a «Y/O» (2002-2003), un proyecto fotográfico en donde el montaje se produce mediante la unión de dos elementos que ponen en juego la diferencia entre ver y leer. El espectador debe interpretar una imagen mediatizada por algún elemento textual y construir un sentido distinto, diferido y alejado, arrojado fuera de sí, siempre en movimiento y escasamente identificable con la univocidad arbitraria de lo lingüístico. Este nuevo montaje que une la imagen a un signo de otro código remite a la lógica dialéctica de la suspensión en donde no se trata de decidir entre una oposición sino de aceptar la simultaneidad y la contradicción. 


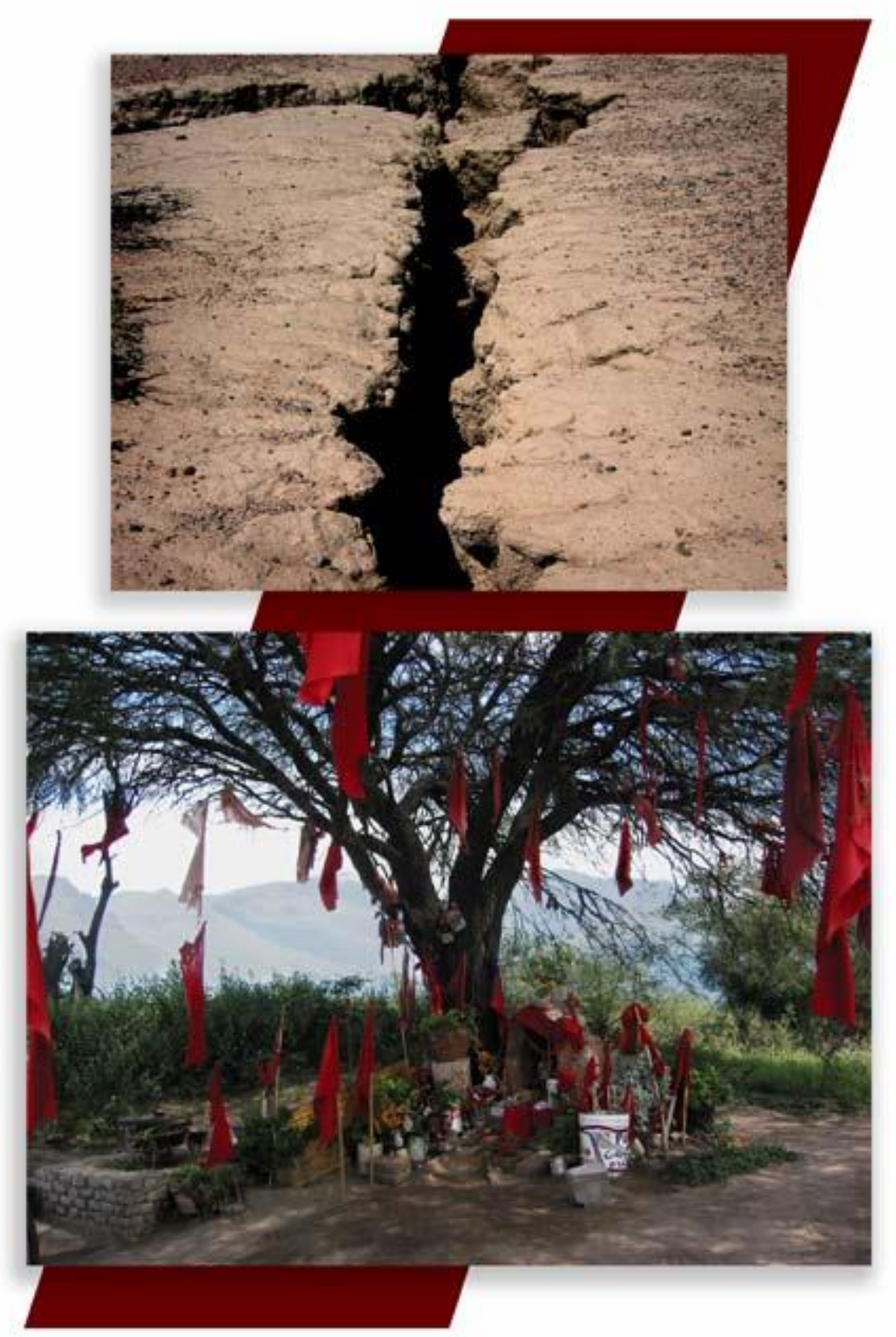

Figura 5. Difunta Correa, disponible en: $<$ http://www.leandrokatz.com/Pages/And_Or\%20Y_O.html>.

Finalmente, los cuerpos son también la materia de estos dípticos que se excriben en el extremo del sentido y que eligen ser representados a partir de una ausencia que se hace presente como fantasma. La difunta correa, los templos en ruinas, las cruces de los cementerios forman la materia visual intervenida por la lógica simbólica del lenguaje textual. Así presentados, los dípticos animan al pasaje, alientan el movimiento de la mirada que debe reconstruir una narración contenida. Como en los haikus, género poético que en alguna oportunidad el mismo artista comparó con los glifos mayas, el díptico condensa sentidos que deben ser desplegados en un relato subjetivo capaz de desenvolver la naturaleza 
paradigmática del signo y darle un desarrollo en extensión. Los cuerpos así representados recuperan el sentido que les fue expropiado ya sea por los mecanismos del poder, el ejército frente a la guerrilla, o por la normatividad arbitraria de un código lingüístico. Así estos cuerpos atravesados por la imagen son cuerpos marcados, cuerpos excritos que se dirigen al afuera para contar la historia amenazada de su existencia.

\section{BIBLIOGRAFÍA}

Agamben, G. (2017), Homo sacer. El poder soberano y la vida desnuda, Buenos Aires, Adriana Hidalgo. (trad. por Costa, F., Il potere soverano e la vita nuda. Homo sacer, Torino, Enaudi, 1995).

BARTHES, R. (1989), La cámara lúcida. Nota sobre la fotografía, Madrid, Paidós. (trad. de Sala Sanahuja, J., La Chambre Claire, Paris, Gallimar, 1980).

Berger, J. Che Guevara muerto [en línea]. Buenos Aires: Fundación PROA, 1 de mayo de 2018 [Consulta: 13 de noviembre de 2019]. Disponible en: $<$ https://www.proa.org/esp/exhibicion-proa-el-dia-que-me-quierastextos.php\#309>.

FOUCAULT, M. (2002), Vigilar y castigar. El nacimiento de la prisión, Buenos Aires, Siglo XXI. (trad. de Garzón de Camino, A., Surveiller et Punir: Naissance de la prison, Paris, Gallimard, 1975).

FoucAult, M. (2015), Historia de la locura en la época clásica, Buenos Aires, FCE. (trad. de Utrilla, J. J., Folie et déraison. Histoire de la folie à l'âge classique, Paris, Gallimard, 1972).

KATZ, L. El día que me quieras [en línea]. La Habana: Festival Internacional de Cine de La Habana, 1997 [Consulta: 13 de noviembre 2019]. Disponible en: $<$ http://www.leandrokatz.com/Pages/E1\%20Dia\%20Spanish.html>.

KATZ, L. (2007), Exhumación [vídeo], Buenos Aires, Instalación Proa, 1 de mayo de 2018.

KATZ, L. (2018), Proyecto para El día que me quieras [film], Buenos Aires, Fundación PROA, 5 de abril-21 de mayo de 2018.

NANCY, J.-L. (2003), Corpus, Barcelona, Arena.

REYNAUD, B. (2013), «Leandro Katz, una entrevista circular», en Arrebatos, diagonales y rupturas, Kratz, L., Buenos Aires, Fundación Telefónica, 25-34.

SPINOZA, B. (2000), La ética demostrada según el orden geométrico, Buenos Aires, Trotta. (trad. de Domínguez, A., Ethica ordine geometrico demonstrata, Amsterdam, 1924). 